\title{
Physical activity as a global risk factor for non-communicable diseases: time for action, what, why, when, who and how?
}

\author{
Estelle V Lambert (BS, MS, PhD) \\ UCT/MRC Research Unit for Exercise Science and Sports Medicine, Department of Human Biology, Faculty of Health Sciences, University \\ of Cape Town
}

Correspondence to: Estelle Lambert (vicki.lambert@uct.ac.za)

Chronic, non-communicable diseases (NCDs) account for more than two-thirds of global mortality, at least $50 \%$ of which is preventable on the basis of modifiable lifestyle behaviours. In the wake of the UN Global Summit on NCDs, the World Health Organization produced a discussion paper that emphasised the need for a global monitoring framework and voluntary global targets for the prevention and control of NCDs.'

The WHO discussion paper presents 10 suggested voluntary targets including the reduction in deaths due to NCDs, cardiovascular disease and diabetes, an overall reduction in blood pressure and obesity, as well as reduced smoking, alcohol and dietary salt intake, increased screening for cervical cancer and the elimination of trans-fats from the food supply. Physical activity is notable by its absence from this critical list of voluntary global targets for preventing and controlling NCDs.

\section{Physical activity as a global health indicator?}

In a recent blog post, Johanna Ralston, the CEO of the World Heart Federation, commented on this omission of physical activity from the WHO's 'top 10.' 'Physical inactivity is noticeably absent from the most recent iteration of WHO proposed targets, and the question is, if we are to include physical activity in the monitoring framework, how can governments effectively monitor physical activity levels? How can we ensure accurate data?'

She goes on to remind us that 'what gets measured gets done .... and that the controversy concerning how many and which targets will be presented at the World Health Assembly has not yet been resolved'. The major concern regarding the inclusion of physical activity has been the perception that there is no accurate and reliable indicator for physical activity at a population level.

In response to this post, Professor Fiona Bull, Chair of Global Advocacy for Physical Activity (GAPA), from the University of Western Australia, highlighted the work on the development and validation of self-report measures for physical activity, spanning the last decade, involving academics all over the world. Such work includes the International Physical Activity Questionnaire (IPAQ) and the Global Physical Activity Questionnaire (GPAQ). Bull reminds us that 'both instruments have been tested in a large number of countries - including those from low and middle-income settings (LMICs)'.

Further, both instruments measure activity in multiple domains, such as work, transport and leisure, which is important, as work and transport patterns are rapidly changing in LMICs. Professor Bull further points out that 'this characteristic is particularly useful for monitoring and influencing policy and practice - particularly in relation to urban design and development. ${ }^{2}$ These instruments have been used in over 130 countries, including South Africa, and it is through this type of surveillance that we have been able to characterise the burden associated with physical inactivity.
Finally, Professor Bull emphasises 'the need to defend and advocate for the importance of including physical activity as a global indicator ... and that GAPA (Global Advocacy for Physical Activity, a Council of the International Society of Physical Activity and Health) has suggested the following voluntary target for physical activity, which is consistent with the policy context and scientific evidence:

'Target: a $10 \%$ relative reduction in the prevalence of insufficient physical activity in adults (defined as less than 150 minutes of moderate physical activity per week or equivalent).

'Indicator: Age-standardized prevalence of insufficient physical activity in adults (defined as less than 150 minutes of moderate physical activity per week or equivalent).'

Moreover, there has been a tremendous amount of work done over the past 2 years, evaluating 'best practice' for population and community-based interventions for increasing physical activity participation, and 'clear actions' which may be adopted and implemented by member states. These have been summarised in a recent publication titled Seven Investments that Work for Physical Activity, available from the GAPA website (http://www.globalpa.org. uk/investments/).

\section{Exercise as a 'vital sign'}

In a recent editorial for the British Journal of Sports Medicine, Robert E Sallis, Chairman of the Exercise is Medicine Advisory Board, argued that it is as important for physicians to ask a patient about their exercise habits as it is to take their blood pressure. In his experience in managed healthcare, every patient has their exercise 'vital sign' taken. They are asked two simple questions: 'On average, how many days/week do you engage in at least some moderate activity?' and 'On those days, on average, how many minutes are you active at this level?'. Sallis acknowledges that accuracy of self-report for some patients may not be ideal, but that doctors and health practitioners have an ethical obligation to measure this 'vital sign' and to counsel their patients on increasing daily levels of physical activity.

\section{Think globally, act locally}

So, we are standing on the edge of a precipice, where NCDs have received global recognition, the prevention and management of which is critical to global well-being. However, at the same time, physical activity is again sidelined, despite over 2 decades of unequivocal evidence linking inactivity to morbidity and mortality, despite having validated global self-report instruments for surveillance of physical activity, and despite having a wealth of information concerning evidence-based practice for 'what works' at a population and community level to increase participation in physical activity. 


\section{What can we do?}

The time for action is now, to 'think globally and act locally!' South Africa has the 4th highest prevalence of physical inactivity in Africa, ${ }^{5}$ using global surveillance instruments. However, we have some promising initiatives. We have a growing regional network, the African Physical Activity Network (AFPAN), which is open to all interested parties, the vision of which is to 'create a network of like-minded individuals and institutions engaged in promoting health through physical activity within the local context of countries and communities of Africa'. (http://www.essm.uct.ac.za/afpan/ )

We have an active South African Sports Medicine Association, which at present provides regional leadership for Exercise is Medicine, promoting exercise and physical activity as a 'vital sign'. In addition, we have support at a policy level. The South African government, through the Department of Health, is currently drafting, in consultation with other sectors, a national plan for physical activity, and the Department of Education has re-emphasised the importance of physical education. Many NGOs operating in our region promote health for children and youth through participation in sport.

It is timeous for each of us, in our sphere of influence, to promote the importance of physical activity, thereby to reduce the burden of disease associated with inactivity. Whether we consult with urban planners, write a letter to Parliament or the World Health Assembly, or simply teach students, guide and motivate patients, the message is the same ... 'to accumulate at least 30 minutes of moderate-to-vigorous activity on most, preferably all, days of the week'. As Professor Mike Evans asks: 'Can you limit the amount of sitting and sleeping you do to just 23 and $1 / 2$ hours every day?' It's the single most important decision one can make to improve health. ${ }^{6}$

\section{REFERENCES}

1. WHO Discussion Paper: A Comprehensive Global Monitoring Framework and Voluntary Global Targets For The Prevention And Control Of NCDs. http://www. who.int/nmh/events/2011/consultation_dec_2011/WHO_Discussion_Paper FINAL.pdf (accessed 6 February 2012).

2. Ralston J. Developing targets for NCDs: Can we Measure Physical Activity? http:// world-heart-federation.org/blog/2012/01/26/developing-targets-for-ncds-can-wemeasure-physical-activity/ (accessed 6 February 2012).

3. Joubert J, Norman R, Lambert EV, et al. Estimating the burden of disease attributable to physical inactivity in South Africa in 2000. S Afr Med J 2007;97:725-731.

4. Global Advocacy for Physical Activity (GAPA) the Advocacy Council of the International Society for Physical Activity and Health (ISPAH). NCD Prevention: Investments that Work for Physical Activity. February 2011. www.globalpa.org.uk/ investmentsthatwork (accessed 6 February 2012).

5. Sallis R. Developing healthcare systems to support exercise: exercise as the fifth vital sign. Br J Sports Med 2011;45:473-474.

6. Evans M. 23 and 1/2 hours: What is the single best thing we can do for our health? http://www.youtube.com/watch?v=aUaInS6HIGo (accessed 6 February, 2012) 